\title{
Chronic fatigue syndrome in the emergency department
}

This article was published in the following Dove Press journal: Open Access Emergency Medicine

\author{
Christian R Timbol* \\ James N Baraniuk* \\ Division of Rheumatology, \\ Immunology and Allergy, Georgetown \\ University, Washington, DC, USA \\ *Both authors contributed equally to \\ this work
}

Correspondence: James N Baraniuk Division of Rheumatology, Immunology and Allergy, Georgetown University, Room 3004F, 3rd Floor, PHC Building, 3800 Reservoir Road NW, Washington, DC 20007-2196, USA

$\mathrm{Tel}+\mid 202687823$ |

Fax + I 2026879886

Email baraniuj@georgetown.edu
Purpose: Chronic fatigue syndrome (CFS) is a debilitating disease characterized by fatigue, postexertional malaise, cognitive dysfunction, sleep disturbances, and widespread pain. A pilot, online survey was used to determine the common presentations of CFS patients in the emergency department (ED) and attitudes about their encounters.

Methods: The anonymous survey was created to score the severity of core CFS symptoms, reasons for going to the $\mathrm{ED}$, and Likert scales to grade attitudes and impressions of care. Open text fields were qualitatively categorized to determine common themes about encounters.

Results: Fifty-nine percent of respondents with physician-diagnosed CFS (total $n=282$ ) had gone to an ED. One-third of ED presentations were consistent with orthostatic intolerance; $42 \%$ of participants were dismissed as having psychosomatic complaints. ED staff were not knowledgeable about CFS. Encounters were unfavorable (3.6 on 10-point scale). The remaining 41\% of subjects did not go to ED, stating nothing could be done or they would not be taken seriously. CFS subjects can be identified by a CFS questionnaire and the prolonged presence ( $>6$ months) of unremitting fatigue, cognitive, sleep, and postexertional malaise problems.

Conclusion: This is the first investigation of the presentation of CFS in the ED and indicates the importance of orthostatic intolerance as the most frequent acute cause for a visit. The selfreport CFS questionnaire may be useful as a screening instrument in the ED. Education of ED staff about modern concepts of CFS is necessary to improve patient and staff satisfaction. Guidance is provided for the diagnosis and treatment of CFS in these challenging encounters. Keywords: patient satisfaction, orthostatic intolerance, postexertional malaise, myalgic encephalomyelitis, systemic exertion intolerance disease, SEID

\section{Introduction}

Chronic fatigue syndrome (CFS) is a debilitating condition that can present with a myriad of somatic symptoms in the emergency department (ED). ${ }^{1}$ We examined these presentations in a cross-sectional manner using an online questionnaire in physiciandiagnosed CFS subjects. Patients' comments about their ED experiences were qualitatively assessed. These findings are relevant to the unique, time-consuming challenges of the CFS patient-ED physician interaction in the fast-paced environment of the ED.

Patient satisfaction studies have examined ED-related factors such as wait time, ${ }^{2}$ time pressure and frequent interruptions, ${ }^{3}$ staff knowledge levels, and accurate information delivery to the patient. ${ }^{4,5}$ These factors negatively impact the quality of interactions and lead to patient dissatisfaction. ${ }^{6}$ Disease-specific factors are less well evaluated. The skepticism about the psychological underpinnings of CFS and the high rates of depression and anxiety in ED patients ${ }^{7,8}$ have the potential to lead to misdiagnosis 
of CFS as a psychosomatic disorder. Staff have negative attitudes toward patients with poorly understood conditions such as substance abuse ${ }^{9}$ and CFS. The limited information and ongoing debate into the etiology of CFS has contributed to patient experiences of stigmatization and delegitimization by health care providers and loved ones. ${ }^{10,11}$ These factors make it imperative to understand the presentation of CFS in the ED and to educate ED staff about CFS.

The most commonly used definition is the 1994 Centers for Disease Control "Fukuda" criteria of $>6$ months of disabling fatigue ( $>50 \%$ reduction in activity or productivity) plus four of eight ancillary consensus complaints: 1) short-term memory or concentration problems, 2) sore throat, 3) sore lymph nodes, 4) myalgia, 5) arthralgia, 6) headache with onset after the fatigue, 7) sleep disturbances, and 8) postexertional malaise (PEM). ${ }^{12}$ Exclusion of chronic medical and psychiatric diseases is an important step for clarifying the ambiguities in this definition. ${ }^{13,14}$ Older traditions included neurasthenia as a psychiatric component ${ }^{15}$ and acute viral infections with low-grade fever that did not resolve within 6 months. ${ }^{16}$ The infectious legacy remains in the International Classification of Diseases revision 10 coding of CFS as "Post-viral fatigue syndrome" (G93.3). ${ }^{17}$ However, this may not encompass gradual onset, disabling fatigue. The newer Canadian Consensus Criteria emphasize PEM, add autonomic dysfunction and orthostatic intolerance (eg, postural orthostatic tachycardia syndrome $)^{18}$ to the criteria, and advocate maintaining the name myalgic encephalomyelitis. ${ }^{19,20}$ An evidence-based analysis by the Institute of Medicine renamed the syndrome "Systemic Exertion Intolerance Disease" to emphasize the disability, fatigue, PEM, cognitive dysfunction, and orthostatic intolerance. ${ }^{21-23}$

To date, no studies have examined CFS in the ED. We have operationalized the 1994 CFS criteria as an online questionnaire that can quickly provide guidance about the diagnosis. ${ }^{24}$ This instrument was used to assess CFS symptom severity in a crosssectional online population and to distinguish CFS from chronic idiopathic fatigue (significant fatigue without other symptoms) and CFS-like with insufficient fatigue (positive review of systems but without fatigue) subjects. ${ }^{25}$ Additional questions that were evaluated may help distinguish CFS from other conditions in the differential diagnosis ${ }^{26}$ such as depression ${ }^{14}$ and Gulf War Illness. ${ }^{27}$ Free text comments were analyzed to describe attitudes of CFS patients about their interactions in EDs.

\section{Subjects and methods Subjects}

An email describing the project, questionnaire, and the survey link was sent to a Listserv of previously examined research participants who had physician-diagnosed CFS. The materials were further disseminated by the CFS patients via word of mouth, social media, support groups, and online forums. All respondents completed the questionnaire online and remained totally anonymous.

The study was approved by the Georgetown University Institutional Review Board (IRB \#2015-1013).

\section{Survey items}

The survey was created and disseminated using Google Forms. ${ }^{28}$ Items measured the severities of CFS symptoms, ${ }^{24}$ past ED experiences, opinions regarding ED staff and attitudes, and demographics. Participants had to respond to each item in order to progress to the next question. As a result, all of the submitted questionnaires were $100 \%$ complete.

CFS symptom severities were assessed using a previously validated questionnaire ${ }^{24}$ that was based on the 1994 Fukuda criteria. ${ }^{12}$ Respondents rated the severity of fatigue and the eight ancillary criteria over the past 6 months using an anchored ordinal scale of 0 (no symptom), 1 (trivial), 2 (mild), 3 (moderate), and 4 (severe) (Table 1). ${ }^{24}$ The sum of the eight ancillary criteria (Sum8) was calculated as a proxy for the diverse ancillary criteria. Receiver operating characteristics found that a Sum 8 threshold $\geq 14$ distinguished CFS from sedentary control subjects. Fatigue Severity can be plotted against Sum8 to create a scattergram. Moderate and severe Fatigue and Sum $8 \geq 14$ divided the graph into four quadrants that show healthy controls (Fatigue = none, trivial, or mild; Sum $8<14$ ), chronic idiopathic fatigue (Fatigue $=$ moderate or severe; Sum8 <14), CFS-like with insufficient fatigue syndrome (CFSLWIFS: Fatigue $=$ none, trivial, or mild; Sum8 $\geq 14$ ), and CFS (Fatigue = moderate or severe; Sum $8 \geq 14$ ) (Table 1). In addition, fatigue and at least four other symptoms had to be present on at least $50 \%$ of the days in the past 6 months because chronicity is a key feature of the CFS diagnosis. ${ }^{12,19-21,23}$ An updated version of the questionnaire is shown in Table 1 and is freely available for clinical use.

CFS subject responses were compared with those of 1,495 female and 2004 male subjects in a nationwide survey that was representative of the US population ${ }^{29}$ in order to show the influence of exclusionary conditions, and a separate group of 706 control and CFS subjects from previous studies in order to reinforce the differences between groups with no, trivial, and mild fatigue (healthy controls and CFSLWIFS) compared with moderate and severe fatigue (CFS and chronic idiopathic fatigue).

Additional questions have been used in clinical practice to help differentiate CFS from depression ${ }^{30}$ but have not been 
Table I CFS questionnaire

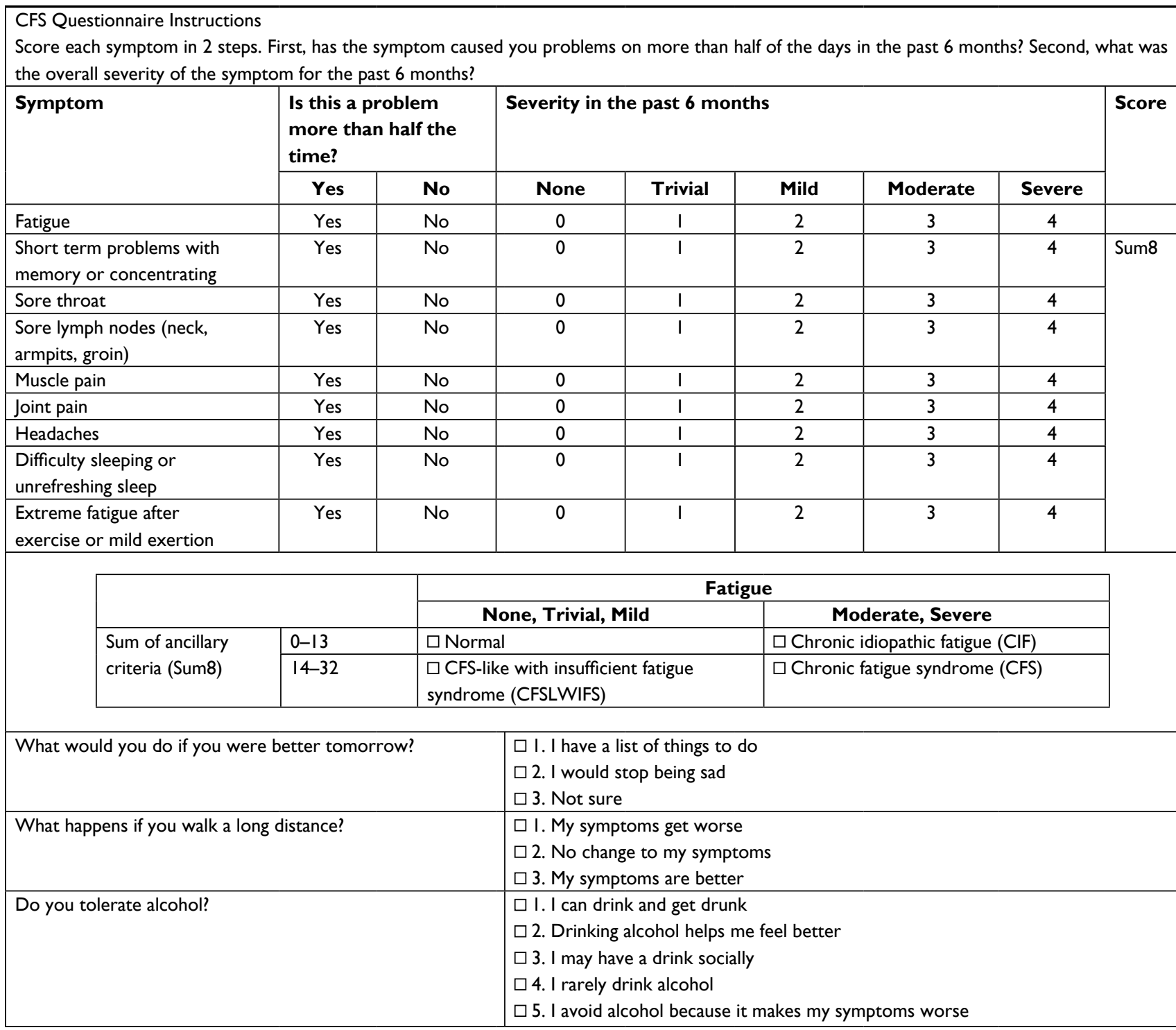

Notes: The severity of fatigue (moderate, severe) and the sum of the other 8 "ancillary" criteria (Sum8 $\geq 14$ ) were cross-referenced to guide the inference of CFS, CIF, and CFSLWIFS.

Abbreviations: CFSLWIFS, CFS-like with insufficient fatigue syndrome; CFS, chronic fatigue syndrome; CIF, chronic idiopathic fatigue.

formally investigated. "What would you do if you were better tomorrow?" addressed the hope, planning, and ambitions of CFS patients in contrast to the flat affect, anhedonia, and bleak view of the future that characterizes major depressive disorder. "What happens if you walk a long distance?" addressed PEM and exertional exhaustion. Exercise has a beneficial effect for the treatment of depression with a moderate effect size of $0.56 .{ }^{31}$ In contrast, CFS subjects develop exertional exhaustion after increased physical effort. "Do you tolerate alcohol?" was added to address patient observations that they no longer tolerated alcohol compared to before the onset of the fatigue. This may identify subjects with acquired metabolomic dysfunction ${ }^{32}$ who may be unable to metabolize ethanol properly, and so may generate excessive acetaldehyde as has been proposed for lowmetabolizing Asians and the so-called chlorpropamide alcohol flushers. ${ }^{33}$ The goal was to determine if CFS subjects had high scores so that these items could be prospectively tested against depression and other chronic illness patient populations.

\section{ED ratings and expectations}

Respondents rated the accuracy of statements related to their ED experiences using an ordinal 10-point Likert scale, anchored by $0=$ "completely unsatisfied" and $10=$ "completely satisfied". Other statements were anchored by $0=$ "completely 
disagree" and $10=$ "completely agree". "Did anyone suggest to you 'it was all in your head'?" addressed the attitudes of ED personnel toward CFS patients during their visits.

Free text comments allowed respondents to list their reasons for making ED visits and impressions of their ED interactions. Comments were reviewed, collated in an iterative manner around similar messages, and finally codified according to common themes. Numbers of comments per theme were computed including the frequencies of the most common symptoms leading to ED visits.

\section{Data analysis}

Responses were cut and pasted into Microsoft Excel. Subjects were divided into those who did (Yes_ED), or did not (No_ ED), go to an ED because of symptoms they believed were related to CFS. Responses by the two groups were compared by two-tailed unpaired Student's $t$-tests with Bonferroni corrections using Excel. Data were reported as medians, mean $\pm 95 \% \mathrm{CI}$, or number (percentage) for categorical variables.

\section{Results}

\section{Subject demographics}

Responses were recorded from September 29, 2015, to November 29, $2015(n=328)$. Data cleaning removed $n=9$ respondents with fatigue scores of 2 (mild, insufficient fatigue), and 37 with fatigue and three or fewer symptoms on less than $50 \%$ of days (not sufficiently chronic). Of the 282 CFS respondents, 59\% (167) reported going to an ED at some time in the past (Yes_ED) (Table 2). The most prevalent range for age was the decade of 40-49 years for both Yes_ED $(n=41,25 \%)$ and No_ED $(n=33$, $29 \%$ ) groups. As anticipated from the demographics of CFS, 86.5\% $(n=244)$ of all respondents were women. Seventy percent $(n=197)$ of all respondents reported having a college degree or beyond. This may have reflected access to the Internet and computer fluency rather than a socioeconomic distinction. The majority of respondents $(n=262,93 \%)$ had a primary care physician. All subjects claimed to have physician-diagnosed CFS but this could not be confirmed in an anonymous fashion online. The groups were equivalent for all demographic measures.

\section{Survey items}

CFS symptom severities were equivalent between the Yes_ED and No_ED groups after correcting for multiple comparisons (Figure 1). Fatigue, exertional exhaustion, and unrefreshing sleep were the most severe and persistent problems in the previous 6 months.
Table 2 Demographics

\begin{tabular}{|c|c|c|c|}
\hline Characteristic & $\begin{array}{l}\text { Yes_ED } \\
(n=167) \\
N(\%)\end{array}$ & $\begin{array}{l}\text { No_ED } \\
(n=\mid \text { | 5) } \\
N(\%)\end{array}$ & $P$-value \\
\hline \multicolumn{4}{|l|}{ Age range (years) } \\
\hline $18-19$ & $2(1 \%)$ & $3(3 \%)$ & 0.93 \\
\hline $20-29$ & $9(5 \%)$ & $9(8 \%)$ & \\
\hline $30-39$ & $29(17 \%)$ & $15(13 \%)$ & \\
\hline $40-49$ & $4 \mathrm{I}(25 \%)$ & $33(29 \%)$ & \\
\hline $50-59$ & $55(16 \%)$ & $28(24 \%)$ & \\
\hline $60-69$ & $26(16 \%)$ & $21(18 \%)$ & \\
\hline $70-75$ & $5(3 \%)$ & $6(5 \%)$ & \\
\hline \multicolumn{4}{|l|}{ Gender } \\
\hline Woman & $145(87 \%)$ & $99(86 \%)$ & 0.86 \\
\hline Man & $22(13 \%)$ & $16(14 \%)$ & \\
\hline \multicolumn{4}{|l|}{ Education } \\
\hline $\begin{array}{l}\text { Less than high } \\
\text { school }\end{array}$ & $2(3 \%)$ & $5(4 \%)$ & 0.86 \\
\hline High school/GED & $10(6 \%)$ & $12(10 \%)$ & \\
\hline Some college & $36(22 \%)$ & $17(15 \%)$ & \\
\hline College degree & $63(38 \%)$ & $40(35 \%)$ & \\
\hline $\begin{array}{l}\text { Master's degree } \\
\text { or beyond }\end{array}$ & $53(32 \%)$ & $4 \mathrm{I}(36 \%)$ & \\
\hline \multicolumn{4}{|l|}{ Medical insurance } \\
\hline Insured & $128(77 \%)$ & 84 (73\%) & 0.50 \\
\hline Uninsured & $39(23 \%)$ & $31(27 \%)$ & \\
\hline \multicolumn{4}{|l|}{$\begin{array}{l}\text { Primary care } \\
\text { physician }\end{array}$} \\
\hline Yes & $158(95 \%)$ & $104(90 \%)$ & 0.18 \\
\hline No & $9(5 \%)$ & II (I0\%) & \\
\hline
\end{tabular}

Notes: The Yes_ED and No_ED groups were equivalent (two-tailed unpaired Student's $t$-tests) reported going to an ED at some time in the past.

Abbreviations: ED, emergency department; GED, General Educational Development; No_ED, did not go to an ED because of symptoms they believed were related to CFS; Yes_ED, did go to an ED because of symptoms they believed were related to CFS.

The sum of the eight ancillary CFS criteria scores (Sum8) was related to Fatigue severity. Sum8 scores were normally distributed in the ED group (median =24) (Figure 2). The separate outpatient group with moderate and severe fatigue who had been screened for exclusionary conditions had Sum8 shifted to the left due to the inclusion of chronic idiopathic fatigue subjects (median $=20$ ).

The distribution in 3,499 subjects representative of the 2004 US population ${ }^{29}$ was shifted toward the left (median $=8$ ) and demonstrated the importance of the exclusionary conditions. Quadrant analysis placed 71\% in the healthy control quadrant, 9.5\% chronic idiopathic fatigue, $8.4 \%$ CFSLWIFS, and $11.3 \%$ in the CFS quadrant. The CFS quadrant included subjects with depression, arthritis, and regular daily exercise that would not be tolerated by CFS patients. These three exclusions were met by $9.3 \%$ of subjects, and so reduced the net prevalence of CFS to $2.0 \%$. This 


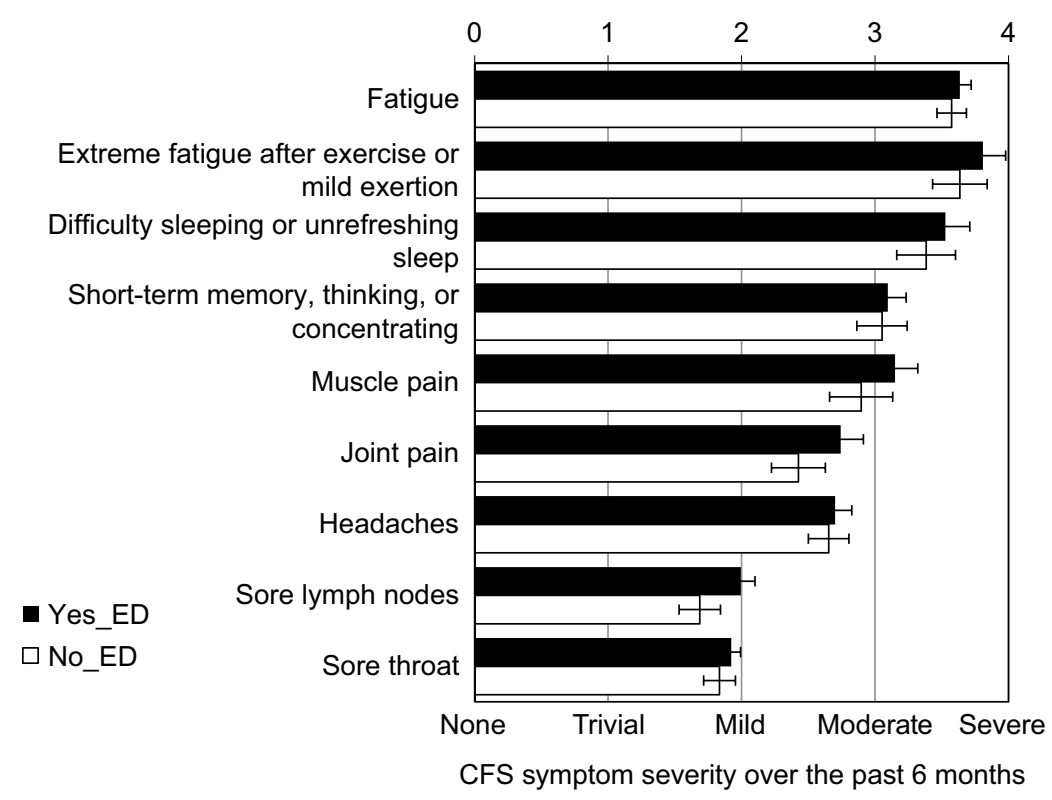

Figure I CFS severity scores for subjects who had visited an ED (black bars, Yes_ED) and those who had never been to an ED (white bars, No_ED) (mean $\pm 95 \%$ CI). Abbreviations: CFS, chronic fatigue syndrome; ED, emergency department; No_ED, did not go to an ED because of symptoms they believed were related to CFS; Yes_ED, did go to an ED because of symptoms they believed were related to CFS.

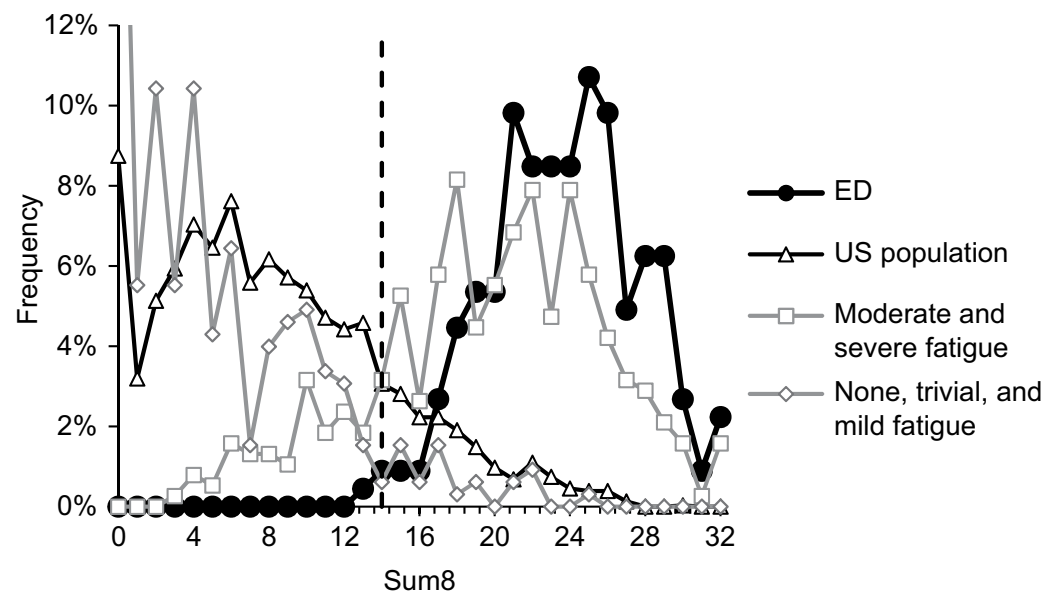

Figure 2 Frequency analysis of Sum8. Severity scores for the eight ancillary CFS criteria were added together (Sum8).

Notes: Survey respondents (ED, black circles and line) had moderate and severe fatigue and high Sum8 scores. The moderate and severe fatigue group included CFS and chronic idiopathic fatigue patients (squares, gray line). The group representative of the US population (triangles, black line) included CFS-like with insufficient fatigue syndrome (low fatigue scores, Sum8 $\geq 14$ ) and subjects with depression and other exclusionary conditions. A second group with low fatigue scores after exclusionary conditions were removed had lower Sum8 scores (diamonds, gray line).

Abbreviations: CFS, chronic fatigue syndrome; ED, Emergency Department.

prevalence would be reduced further by history, physical, and other tests for exclusionary conditions. ${ }^{14}$ For example, a tertiary care referral center found that at least $40 \%$ of putative CFS patients had a chronic medical disease $(47 \%$ of all alternative diagnoses), primary sleep disorders (20\%), and psychological and psychiatric illnesses (15\%). ${ }^{34}$ Most of these would be identified by standard history and physical evaluations in the ED.

CFSLWIFS subjects were relevant to ED care because they present with a positive review of systems but mild or no fatigue. They represent a large group of health care seekers with common but medically unexplained symptoms. ${ }^{35}$

When asked, "What would you do if you were better tomorrow?", $91 \%$ of the Yes_ED group and $83 \%$ of the No_ED group answered they have a list of things to do (Figure 3). Ninety-six percent of Yes_ED and 93\% of No_ED respondents indicated their symptoms were worse if they walked a long distance. This confirmed their exertional exhaustion. In terms of alcohol tolerance, $63 \%$ of Yes_ED group and $43 \%$ of No_ED group noted they avoid alcohol because it makes their symptoms 

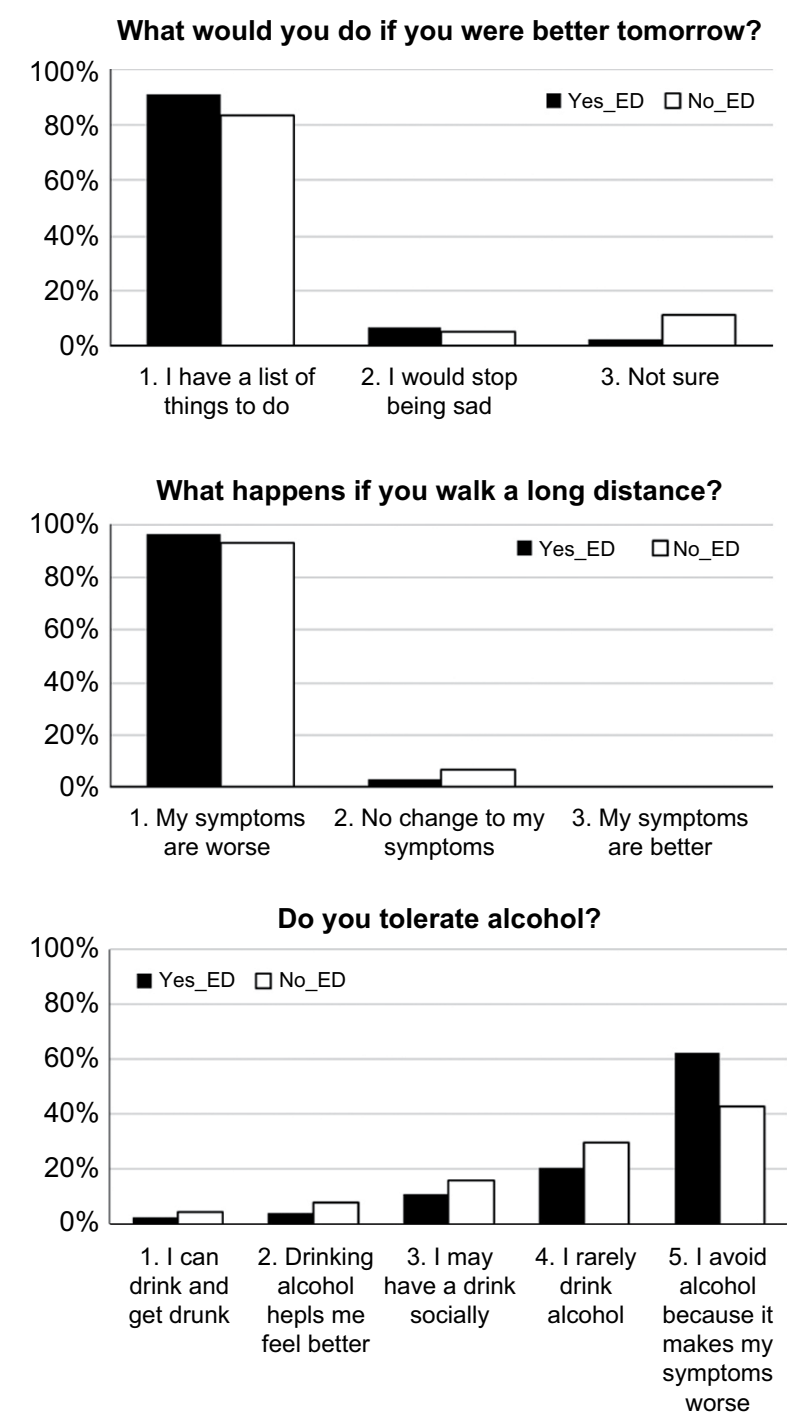

Figure 3 Percentage of responses. Scores were equivalent for the Yes_ED (black bars) and No_ED (white bars) groups. $y$-axes $=\%$ of group.

Abbreviations: ED, emergency department; No_ED, did not go to an ED because of symptoms they believed were related to CFS; Yes_ED, did go to an ED because of symptoms they believed were related to CFS.

worse. There were no correlations between CFS severity scores and responses to these questions. Given the highly skewed responses, these questions will now be assessed for sensitivity and specificity against other populations in future questionnaires.

\section{ED ratings and expectations}

Symptoms at presentation to the ED were evaluated from the free text comments of 167 respondents in the Yes_ED

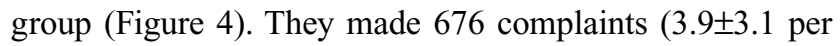
respondent, mean $\pm 95 \% \mathrm{CI}$ ). Orthostatic intolerance was suggested as the leading reason for ED visits because the most prevalent complaints were "dizzy/lightheaded" $(\mathrm{n}=88$, $14 \%)$, "general weakness" $(n=72,12 \%)$, and "fainting" $(n=33$,
$5 \%$ ) (Figure 5). Fatigue and PEM occurred in about $8 \%$ each. Muscle pain ( $8 \%$ ), headache (7\%), and joint pain (5\%) were relatively infrequent and suggested that drug seeking (ie, narcotics) was not a motivation for CFS patients. Headaches were not associated with nausea, vomiting, or visual changes (eg, photophobia). Gastrointestinal issues such as diarrhea or constipation $(n=52,8 \%)$ were common, but these occurred without abdominal pain $(0.2 \%)$, nausea, or vomiting $(0.7 \%)$. "Other" complaints $(\mathrm{n}=58,9 \%)$ included "heart problems" and "heart attack". Cardiovascular disease should be considered in the differential diagnosis. ${ }^{34}$ There were no correlations between CFS severity scores and the number of complaints.

CFS respondents reported the ED staff were not knowledgeable about CFS (mean rating 1.9/10) and were not truly listening to their concerns (3.7/10) (Figure 5). Attribution to stress, anxiety, or other psychological issues had a bimodal distribution, suggesting that half of the personnel had a bias toward a psychosomatic etiology of the complaints (5.7/10). This is consistent with the $41.9 \%$ of CFS patients who were told by ED staff that "it was all in your head". In contrast, CFS patients expected ED staff to know what CFS was $(6.9 / 10)$ and had the expectation that the ED should be able to treat their presenting symptoms (7.2/10). It was not surprising that the overall ED experience scored 3.6 demonstrating general dissatisfaction by CFS patients.

"Did you share the diagnosis of CFS to the ED? If not, "why?" Only 72\% $(n=121)$ of the Yes_ED patients told the ED staff they had CFS. The three most common themes were lack of knowledge or education about CFS by the ED staff ( $n=28,25 \%)$, feelings of being dismissed or not taken seriously $(n=26,23 \%)$, and being told explicitly or inferred that their symptoms were psychological $(n=20,18 \%)$. There was a lack of respect or compassion (16\%), and patients worried they would receive a lower quality of care $(13 \%)$. The other 46 (28\%) in the Yes_ED group did not reveal their CFS diagnosis.

An open comment field allowed respondents to explain a "no" response (Figure 6). One patient statement was,

I did not share I had ME/CFS because if I do my symptoms are dismissed. I'm thought of as a drug seeker, or a hypochondriac. I'm belittled and sent home without treatment.

This statement was codified with feelings of "judgment" $(\mathrm{n}=17,37 \%)$, "care would be affected" $(\mathrm{n}=15,33 \%)$, and being dismissed $(n=10,22 \%)$. The ED physician did not make a diagnosis of CFS in 18/46 (39\%) of the Yes_ED cases who did not reveal their diagnosis.

The most common theme in the No_ED patients $(n=93)$ was, "I knew there was nothing they could do for me" $(n=16$, 


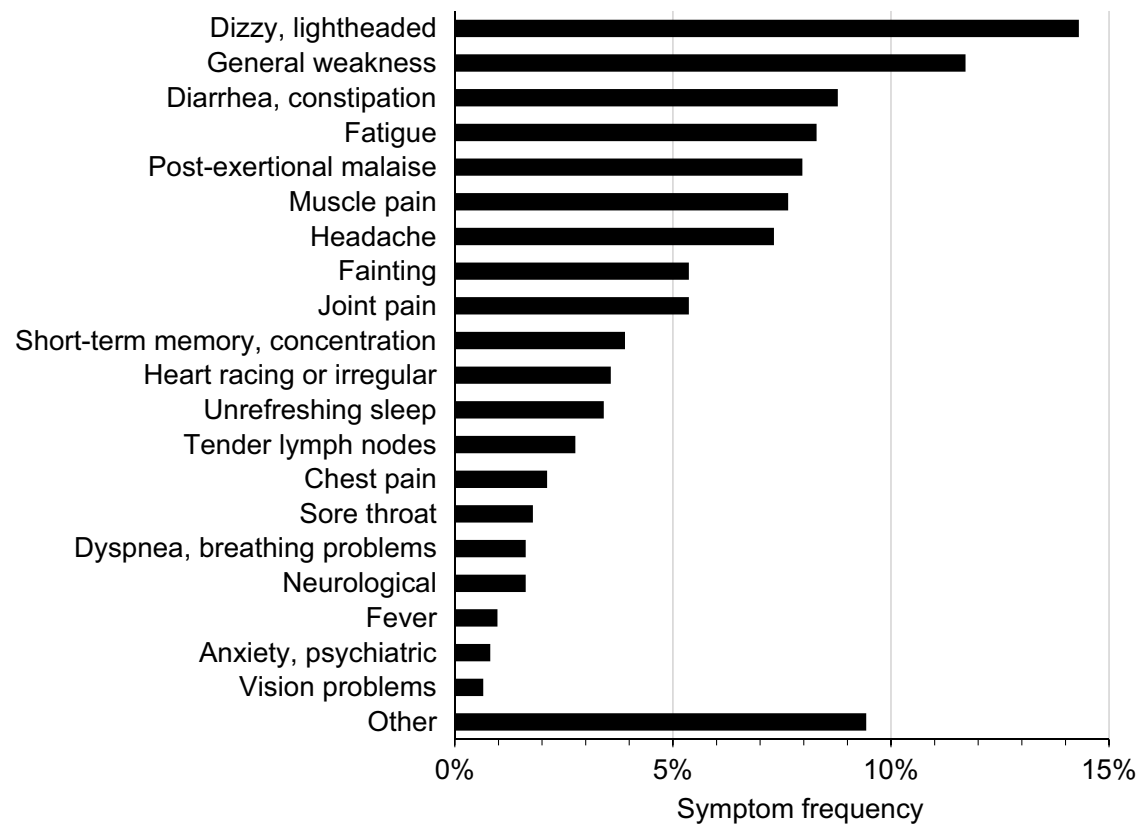

Figure 4 Frequencies of individual free text symptoms at presentation to the emergency department.

ED staff appeared knowledgeable

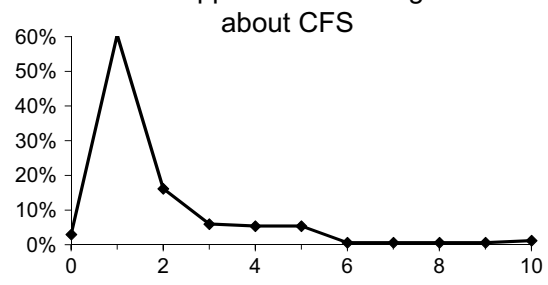

I expect the ED staff to know what

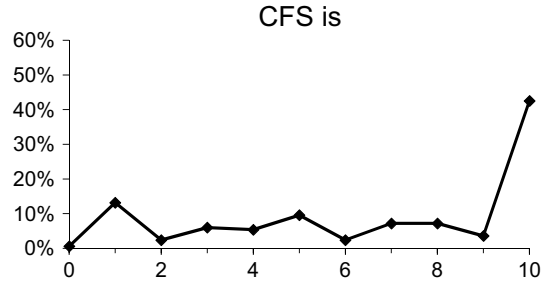

I felt the ED staff were truly listening to my concerns

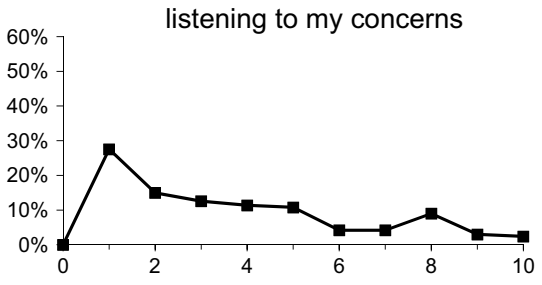

ED should be able to treat my symptoms

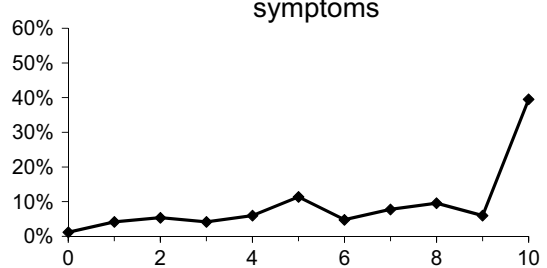

ED staff suggested my issues were psychological, stress, and/or anxiety

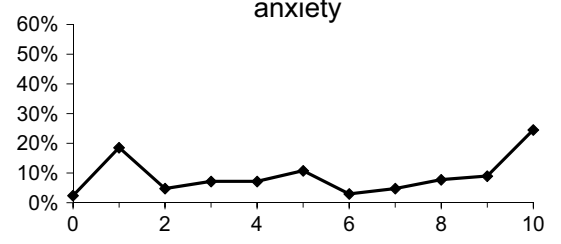

Overall ED experience

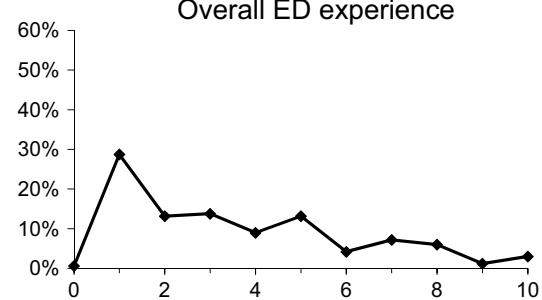

Figure $5 \mathrm{ED}$ ratings and CFS patient expectations.

Notes: The ordinal scale was scored with $0=$ "completely disagree" and $10=$ "completely agree."

Abbreviation: CFS, chronic fatigue syndrome; ED, emergency department.

$17 \%)$, followed by lack of respect or compassion $(n=14$, $15 \%)$ and feelings of being dismissed or not taken seriously $(\mathrm{n}=13,14 \%)$.

\section{Discussion}

The most common symptoms leading to an ED visit were dizziness and lightheadedness. This is consistent with the Canadian ${ }^{19,20}$ and Institute of Medicine ${ }^{21}$ criteria that include orthostatic intolerance (Table 3). Postural orthostatic tachycardia syndrome $(11 \%-13 \% \text { of } \mathrm{CFS})^{18,36,37}$ and idiopathic tachycardia are common in CFS. ${ }^{38}$ When combined with symptoms of general weakness, faintness, and palpitations, orthostatic intolerance accounted for roughly one-third of the complaints leading to ED visits. Acute cardiac, neurological, and other life-threatening causes must be excluded by appropriate examinations before attributing the symptoms to CFS.

Ten respondents reported "feeling better with intravenous fluids" (Figure 6). This is consistent with findings of depleted circulating fluid volume, reduced cardiac end-diastolic volume, stroke volume and cardiac output, ${ }^{39}$ "small heart syndrome", ${ }^{40}$ dysregulated sympathetic vasoconstrictor tone related to brain stem atrophy found by $\mathrm{MRI},{ }^{41}$ and increased 


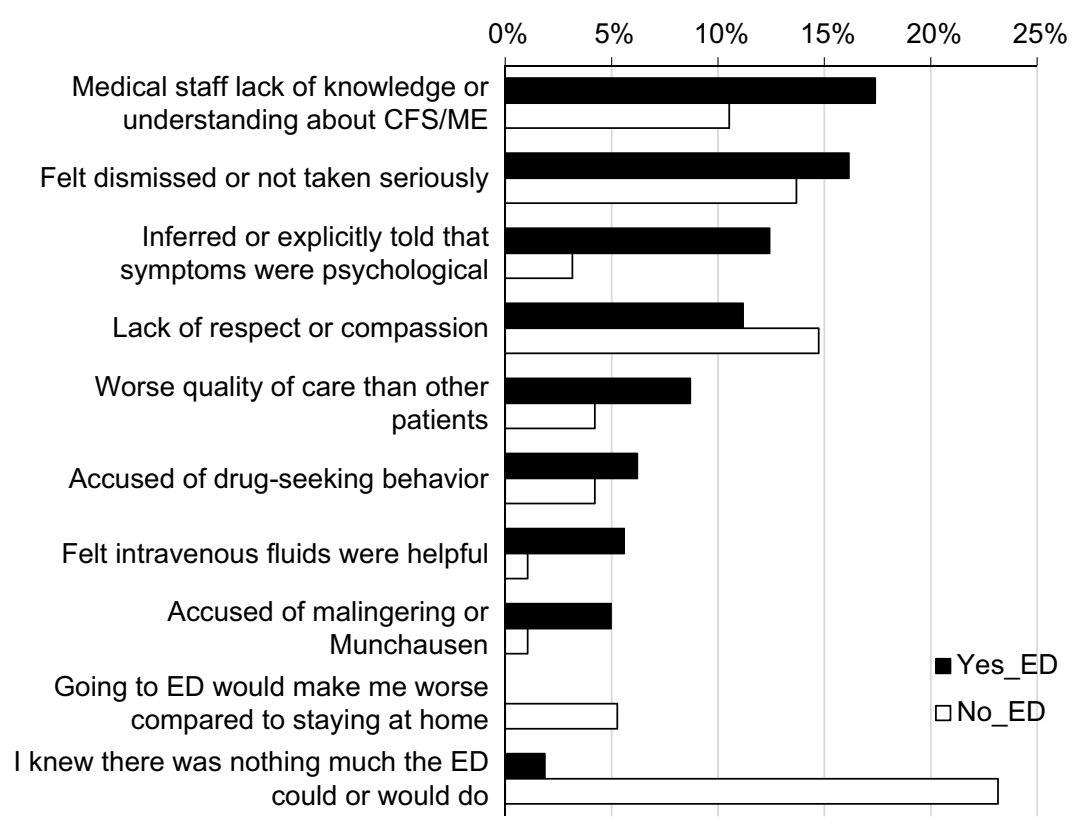

Figure 6 Free text themes. Percentages of subjects responding to each theme were plotted for Yes_ED (black bars) and No_ED (white bars) groups. Abbreviation: CFS, chronic fatigue syndrome; ED, emergency department; ME, myalgic encephalomyelitis; No_ED, did not go to an ED because of symptoms they believed were related to CFS; Yes_ED, did go to an ED because of symptoms they believed were related to CFS.

cholinergic vasodilator effects. ${ }^{42}$ Intravenous fluids are a common recommendation from CFS specialists to ED staff in clinical practice, but their use has not been systematically studied. Given that there are no Food and Drug Associationapproved, CFS-specific treatments, ${ }^{43}$ it is reasonable to consider administering oral or intravenous fluids to acutely alleviate orthostatic intolerance, cognitive impairment, PEM, and fatigue complaints in CFS patients after life-threatening disorders have been ruled out.

Diarrhea and constipation were common presentations, but their etiology in CFS has not been extensively explored. The low prevalence of abdominal pain was surprising. Treatment is directed at symptom control.

Migraine with headache, nausea, vomiting, and visual changes (ie, photophobia) was not a common presentation in our study even though we have estimated that up to $80 \%$ of CFS had migraine ( $n=67) .{ }^{44,45}$ Migraine in CFS was associated with poor memory, dizziness, imbalance, numbness, perceived heart rhythm disturbances, palpitations, noncardiac chest pain, and a high rate of response to sumitriptan. ${ }^{44}$ Migraine and tension headaches were comorbid conditions in $60 \%$. Headaches were often daily or unremitting. Migraine without aura should be considered in the ED and treated appropriately.

Noncardiac chest pain may be due to gastroesophageal reflux or costochondritis, but cardiac causes should be considered if the pulse, blood pressure, or EKG is abnormal. This is particularly important because of the predominance of women and their atypical presentations of angina (eg, nausea). ${ }^{46}$ Diaphoresis is a common component of autonomic dysfunction in CFS. ${ }^{19,20}$ Mortality from cardiovascular and all causes may be significantly higher in CFS than in the overall US population. ${ }^{47}$

Chronic total body pain and fibromyalgia are problematic because the 2011 fibromyalgia criteria assess widespread pain, fatigue, cognitive dysfunction, unrefreshing sleep, and somatic complaints (Table 3). ${ }^{48,49}$ The sign of systemic hyperalgesia (tenderness) that was central to the 1990 criteria $^{50}$ was deleted in $2010 .{ }^{51}$ As a result, the symptom profile is nearly indistinguishable from CFS, leading some to wonder "What is fibromyalgia?". ${ }^{52}$ However, PEM is a defining element of CFS that is not required by fibromyalgia diagnostic criteria.

The criteria for CFS have similarities with the ancillary criteria of depression and somatoform disorders including fatigue, lack of energy, poor concentration, insomnia, and reduced activity (Table 3 ). ${ }^{53,54}$ This may be a superficial subjective oversimplification because major depressive disorder and CFS are distinct entities when their objective findings such as leukocyte mRNA expression patterns are contrasted. ${ }^{55,56}$ CFS is associated with plasma metabolomics changes indicating mitochondrial dysfunction and reduced utilization of amino acids for ATP production. ${ }^{32,57}$ Similar findings are not reported in depression. Screening for depression often uses short questionnaires that emphasize somatic complaints to distinguish depression from healthy subjects. ${ }^{58,59}$ However, questionnaires have high false-positive 
Table 3 Comparison of criteria

\begin{tabular}{|c|c|c|c|c|c|c|}
\hline $\begin{array}{l}\text { Chronic fatigue } \\
\text { syndrome } \\
1994^{a, 12}\end{array}$ & ME $2003^{19,20}$ & $\begin{array}{l}\text { SEID } \\
2015^{21}\end{array}$ & $\begin{array}{l}\text { Gulf War Illness } \\
2000 \text { Kansas }^{c, 27} \\
\text { criteria }^{c, 27}\end{array}$ & $\begin{array}{l}\text { Fibromyalgia } \\
1990 \\
\text { criteria }^{\mathrm{d}, 50}\end{array}$ & $\begin{array}{l}\text { Fibromyalgia } \\
2010 \\
\text { criteriad }^{\mathrm{d}, 51}\end{array}$ & $\begin{array}{l}\text { Depression } \\
\text { DSM-IV-TR }\end{array}$ \\
\hline 6 months & 6 months & 6 months & 6 months & 3 months & I week & 2 weeks \\
\hline Fatigue & Fatigue & Fatigue & Fatigue & & Fatigue & Fatigue \\
\hline Sleep & Sleep & Sleep & Sleep & & Sleep & Sleep \\
\hline $\begin{array}{l}\text { Exertional } \\
\text { exhaustion }\end{array}$ & $\begin{array}{l}\text { Exertional } \\
\text { exhaustion }\end{array}$ & $\begin{array}{l}\text { Exertional } \\
\text { exhaustion }\end{array}$ & $\begin{array}{l}\text { Exertional } \\
\text { exhaustion }\end{array}$ & & & \\
\hline Cognition & Cognition & Cognition $^{b}$ & Cognition & & Cognition & Cognition \\
\hline \multirow[t]{2}{*}{ Headache } & Headache & & Headache & & & \\
\hline & $\begin{array}{l}\text { Orthostatic } \\
\text { intolerance }\end{array}$ & $\begin{array}{l}\text { Orthostatic } \\
\text { intolerance }^{\mathrm{b}}\end{array}$ & Dizzy, Lightheaded & & & \\
\hline $\begin{array}{l}\text { Myalgia, } \\
\text { arthralgia }\end{array}$ & $\begin{array}{l}\text { Widespread } \\
\text { pain }\end{array}$ & & Myalgia, arthralgia & $\begin{array}{l}\text { Myalgia, } \\
\text { arthralgia }\end{array}$ & $\begin{array}{l}\text { Myalgia, } \\
\text { arthralgia }\end{array}$ & \\
\hline Sore throat & & & & & Somatic & \\
\hline \multirow[t]{11}{*}{ Lymph nodes } & & & & & complaints & \\
\hline & $\begin{array}{l}\text { Irritable bowel } \\
\text { syndrome }\end{array}$ & & Gastrointestinal & & & \\
\hline & $\begin{array}{l}\text { Recurrent flu- } \\
\text { like illnesses }\end{array}$ & & Respiratory & & & \\
\hline & $\begin{array}{l}\text { Sensations of } \\
\text { temperature } \\
\text { instability }\end{array}$ & & Skin rash & & & \\
\hline & & & & $\begin{array}{l}\text { Systemic } \\
\text { hyperalgesia }^{d}\end{array}$ & $\begin{array}{l}\text { Testing for } \\
\text { tenderness no } \\
\text { longer required }\end{array}$ & \\
\hline & \multirow{6}{*}{$\begin{array}{l}\text { Major } \\
\text { depression is } \\
\text { exclusionary }\end{array}$} & & \multirow[t]{6}{*}{$\begin{array}{l}\text { Depressed by self- } \\
\text { report }\end{array}$} & & & Depressed affect \\
\hline & & & & & & $\begin{array}{l}\text { Decreased interest } \\
\text { or pleasure }\end{array}$ \\
\hline & & & & & & Weight/appetite \\
\hline & & & & & & Change in activity \\
\hline & & & & & & $\begin{array}{l}\text { Guilt/ } \\
\text { worthlessness }\end{array}$ \\
\hline & & & & & & Suicidality \\
\hline
\end{tabular}

Notes: Fatigue, sleep, and cognitive difficulties are shared by all of the conditions. Exertional exhaustion/postexertional malaise was shared by CFS, myalgic encephalomyelitis (ME), systemic exertion exertion intolerance disease (SEID), and Gulf War Illness, and were absent in fibromyalgia and depression criteria. Distinctive defining features are the durations of symptoms; visceral complaints and 199I Persian Gulf War exposures in GWI; systemic hyperalgesia measured by thumb pressure and tender points in the 1990 fibromyalgia criteria but removal of this sign in the 2010 fibromyalgia criteria; and depressed affect, anhedonia, guilt/worthlessness, and suicidal ideation in depression.

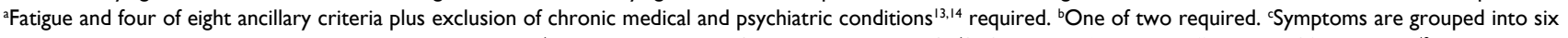
domains, with GWI identified by having symptoms in $\geq 3 / 6$. 'Pain plus tenderness (systemic hyperalgesia). "Self-reported "depression" added in $201 \mathrm{I}$ criteria. ${ }^{48}$

Abbreviations: CFS, chronic fatigue syndrome; DSM-IV-TR, Diagnostic and Statistical Manual of Mental Disorders, Fourth Edition, Text Revision; GWI, Gulf War Illness.

rates in conditions that are diagnosed based on unexplained somatic complaints. Questionnaires do not follow the psychiatric practice of first diagnosing depressed affect and anhedonia, with secondary confirmation by somatic complaints. Hoyer and David propose a better approach to assess depression in the $\mathrm{ED}^{60}$ including the mnemonic "In $\mathrm{SAD}$ CAGES" (loss of Interest in activities/Sleep disturbance/ Appetite change/Depressed mood/difficulty Concentrating/Activity level change/excessive Guilt/loss of Energy/ Suicidal thoughts, plan, or attempt). ${ }^{61}$ If the patient answers affirmatively to five or more of the nine symptoms having been present on a daily basis for 2 weeks, depression should remain in the patient's differential diagnosis. The possibility of depression should be discussed with the patient and an appropriate referral made. Of course, if a patient might be suicidal, emergent psychiatric consultation is indicated." ${ }^{59-61}$ Inappropriate use of antidepressant medications in $\mathrm{CFS}^{62}$ may lead to adverse effects such as increased appetite, weight gain, and iatrogenic type II diabetes in subjects who cannot tolerate exercise to reverse the obesity.

CFS respondents were dissatisfied with their ED visits. Their open text themes showed that they expected that ED health care providers would have some knowledge about CFS and be able to treat their symptoms. These expectations were not met as judged by the lack of knowledge and treatment strategies by ED staff, and the comments from the No_ED 
respondents that they did not go to the ED for their CFS symptoms because "they knew nothing could or would be done for them". CFS patients felt they were being treated with a dismissive lack of respect that could sink to accusations of drug-seeking behavior and Munchausen syndrome. The themes in our study are consistent with those voiced by CFS patients in other settings. ${ }^{10,11}$

The CFS Severity Score Questionnaire (Table 1) serves as a quick self-report instrument to help narrow the differential diagnosis of nociceptive, interoceptive, and fatiguing illnesses to CFS (Table 4). Follow-up questioning should focus on exclusionary conditions and the positive features of chronic fatigue, PEM, and unrefreshing sleep that specifically identify CFS. The fatigue must have been present for more than 6 months, and medical or psychiatric causes have been evaluated and ruled out. Many CFS patients carry reams of medical records with them to doctor and ED visits. Instead, they can be encouraged to write a one-page summary that encapsulates their history, medications, and drug adverse events, and clearly states the specific reason for this particular visit. PEM/exertional exhaustion is almost the sine qua non of CFS. In normal subjects, excessive exertion is fatiguing and leads to sensations of pain and bodily heaviness. Cognitive processes inhibit expenditure of further effort in order to conserve physical and cognitive reserves and prevent total exhaustion. ${ }^{63}$ The distressing physical and cognitive perceptions improve or disappear completely after a refreshing night of sleep. In contrast to CFS, cognitive, emotional, or physical effort that is more than the patient's usual level can cause a relapse of that patient's typical spectrum of fatigue, cognitive compromise ("brain fog"), pain, and orthostatic intolerance. The onset

Table 4 Differential diagnosis of CFS

\begin{tabular}{|c|c|c|}
\hline & Excludes CFS & May be comorbid with CFS \\
\hline Endocrine & $\begin{array}{l}\text { Hypothyroidism, hyperthyroidism, adrenal insufficiency, } \\
\text { diabetes mellitus, electrolyte imbalance }\end{array}$ & $\begin{array}{l}\text { Controlled thyroid disease, controlled } \\
\text { diabetes }\end{array}$ \\
\hline Gastrointestinal & Celiac disease, Crohn’s disease, hepatitis, BMI >40 & Irritable bowel syndrome \\
\hline Chronic infections & $\begin{array}{l}\text { Chronic infectious mononucleosis, Epstein-Barr and } \\
\text { other Herpes virus infections, tuberculosis including } \\
\text { Avian-intracellulare, brucellosis, giardiasis, hepatitis } \\
\text { B and C, HIV infection, Lyme disease, Q fever, } \\
\text { toxoplasmosis, cytomegalovirus }\end{array}$ & \\
\hline Malignancy & $\begin{array}{l}\text { Hodgkin's lymphoma, pituitary tumor, occult malignancy, } \\
\text { cachexia, postchemotherapy fatigue syndrome }\end{array}$ & \\
\hline Respiratory & $\begin{array}{l}\text { Sarcoidosis, bronchiolitis obliterans, pulmonary } \\
\text { hypertension }\end{array}$ & $\begin{array}{l}\text { CFS may continue despite treatment } \\
\text { of sleep apnea }\end{array}$ \\
\hline Rheumatological & $\begin{array}{l}\text { Sjogren's syndrome, systemic lupus erythematosus, } \\
\text { rheumatoid arthritis, polymyalgia rheumatic, giant cell } \\
\text { arteritis, polymyositis, chronic regional pain syndrome }\end{array}$ & Fibromyalgia \\
\hline Cardiac & $\begin{array}{l}\text { Cardiomyopathy, endocarditis, constrictive pericarditis, } \\
\text { valvular disease, congestive heart failure }\end{array}$ & Idiopathic tachycardia syndrome \\
\hline Neuromuscular & $\begin{array}{l}\text { Neurological causes of autonomic dysfunction } \\
\text { and orthostatic intolerance, mild traumatic brain } \\
\text { injury, postconcussion syndrome, multiple sclerosis, } \\
\text { narcolepsy, myasthenia gravis, Parkinson's disease }\end{array}$ & $\begin{array}{l}\text { Postural orthostatic tachycardia } \\
\text { syndrome, central sensitization } \\
\text { syndromes }\end{array}$ \\
\hline Psychiatric & $\begin{array}{l}\text { Major depressive disorder especially if melancholic or } \\
\text { psychotic features, generalized anxiety disorder, panic } \\
\text { attacks, post-traumatic stress disorder, hypochondriasis, } \\
\text { schizophrenia, bipolar disorder, active anorexia nervosa } \\
\text { or bulimia nervosa, alcohol or substance abuse }\end{array}$ & $\begin{array}{l}\text { Psychological dysfunction is common } \\
\text { in CFS but may be a consequence } \\
\text { of disabilities, limitations, and coping } \\
\text { strategies }\end{array}$ \\
\hline Medications & $\begin{array}{l}\text { Adverse effects of psychoactive, antihypertensive, pain } \\
\text { and other drugs. Dehydration, volume depletion, or } \\
\text { electrolyte imbalance (eg, due to diuretics). }\end{array}$ & $\begin{array}{l}\text { CFS subjects are often more sensitive } \\
\text { to psychoactive medications and } \\
\text { may need to start at low doses with } \\
\text { gradual increases over time }\end{array}$ \\
\hline Other & $\begin{array}{l}\text { Chronic organophosphate poisoning, heavy metal } \\
\text { toxicity, systemic mastocytosis, other chronic medical } \\
\text { diseases with pathophysiologically defined tissue } \\
\text { inflammation or damage }\end{array}$ & Gulf War Illness \\
\hline
\end{tabular}

Notes: Up to $70 \%$ of presumed CFS subjects have exclusionary conditions after referral to tertiary care facilities. In general, CFS is excluded by chronic medical or active psychiatric disease. CFS can be a comorbid condition with controlled endocrine and other illnesses.

Abbreviations: BMI, body mass index; CFS, chronic fatigue syndrome. 
may be immediate or may be delayed up to 24 hours, which is highly unusual in healthy subjects. CFS patients may have to rest for several days before they can resume usual daily activities. Sleep is not refreshing or restorative at the best of times for CFS patients and is not refreshing after exertion. In contrast to healthy subjects who are refreshed after sleeping, CFS PEM symptoms may be delayed until after a night's sleep.

Our study design has inherent limitations. Self-reporting of past experiences are subject to recall bias. However, given the paucity of information regarding the presentations of CFS patients to the ED, this pilot study serves as a starting point for future investigations into this topic. The gender distribution and peak age range were representative of the general CFS population, but our subjects had higher education levels than other reports. ${ }^{64}$ This may indicate a selection bias due to the online format, Internet survey dissemination, and access to, and skill working with, computers. While the CFS questionnaire has been used extensively online, the other inquiries were unique to this study and will need future validation. It is possible that some respondents had other conditions that would exclude CFS. However, the high severity of chronic fatigue, previous diagnosis by a physician, and contact through the Listserve makes CFS the more likely diagnosis. The number of negative comments about ED attitudes and experiences from Yes_ED patients would be biased if the only respondents to fill out the surveys were those who wanted to report negative encounters. However, the comments by the No_ED and Yes_ED subjects who did not reveal their CFS diagnosis were also similar and consistent. CFS patients had bad perceptions of the dismissive attitudes of ED staff, their psychosomatic bias, and deficient knowledge about CFS. These messages are clear despite the limitations of this pilot study.

\section{Clinical evaluation}

The diagnosis of chronic fatigue syndrome can be scrutinized using the scoring sheet in Table 1 that is based on the 1994 Centers for Disease Control criteria. ${ }^{24,29}$ The fatigue must have been moderate or severe for at least 6 months, with other symptoms starting after the fatigue. PEM is a key indicator of CFS (Figures 1 and 4). Cognitive, emotional, or physical exertion is likely to cause a relapse of cognitive, pain, interoceptive, sleep, and fatigue dysfunction in CFS. The onset may be delayed hours or until the day after the exertion. This is very different from the pattern of recovery in virtually all other diseases and in healthy subjects. The CFS patient has likely had extensive blood work and other studies, and has seen many specialists. They may turn to the ED as a last resort hoping for some novel therapy. Unfortunately, their expectations are generally not met by knowledge or compassion, and lead to poor patient satisfaction. ED staff are not knowledgeable about CFS and were deemed to be disdainful of CFS patients. Forty-two percent of patients were told, "It is all in your head", which is not a constructive approach to enhance medical care. If CFS is suspected, then targeted questions about the chronic nature of the fatigue, past experiences with PEM, and previous medical evaluations coupled with focused review of the patient's pertinent medical reports and records, followed by selected blood tests and EKG, as appropriate, are likely to determine whether exclusionary conditions of relevance to the visit have been ruled out. These include hypothyroidism, cardiac disease, anemia, depression, effects of psychoactive and other drugs, and other chronic medical diseases (Table 4). ${ }^{13,14,34}$ Orthostatic intolerance was the leading cause for ED visits in this study; intravenous or oral fluids in a supportive, nonconfrontational setting may be beneficial after life-threatening conditions have been ruled out. New findings of cardiac, brain stem, autonomic, immune cell, and metabolomics alterations are beginning to delineate the pathophysiology of this condition ${ }^{31,38-41,51}$ and will lead to future phenotyping of CFS subtypes and, hopefully, to biomarkers for diagnosis and targeted drug therapies.

\section{Conclusion}

CFS patients present to the ED with a complex list of chronic symptoms, but the acute reasons for presentation are related to orthostatic intolerance, fatigue, PEM, and diarrhea (Figure 4). Standard history and physical examination should identify serious cardiovascular and other events, and allow the exclusion of cases with other chronic medical and psychiatric diseases from the differential diagnosis (Tables 3 and 4). The CFS Symptom Severity Questionnaire and supporting questions (Table 1) provide a clinical guide and self-report instrument for inferring CFS in the busy ED setting. A barrier to care was the lack of knowledge of ED staff about CFS, and focus on psychosomatic etiology so that $43 \%$ of patients were told, "It is all in your head". A successful and efficient ED encounter is more likely if 1) ED staff are cognizant of CFS, 2) acute life-threatening conditions are identified and treated, 3) chronic medical and psychiatric conditions are addressed by standard history and physical examination, 4) CFS is diagnosed by its characteristic features, and 5) orthostasis, diarrhea, and other acute symptoms are treated in standard fashion. 


\section{Ethics, consent, and permissions}

Human participants completed an online questionnaire in an anonymous fashion. No personal information was obtained. Subjects approved of the informed consent in order to participate in the study. The study was approved by the Georgetown University Institutional Review Board and conformed to the Declaration of Helsinki.

\section{Data sharing statement}

The datasets used and/or analyzed during the current study are available from the corresponding author on reasonable request.

\section{Acknowledgments}

Ms Amber Surian, MS, provided editorial and other support. Funding was provided by The Sergeant Sullivan Circle, Dr. Barbara Cottone, the Dean Clarke Bridge Prize, and the National Institute of Neurological Diseases and Stroke (RO1NS085131). The design of the study and collection, analysis, and interpretation of data and writing of the manuscript were independent of all funders.

\section{Author contributions}

CRT conceived of the study, obtained IRB approval, created the questionnaires, conducted the program, performed data analysis, and wrote the draft manuscript while a student at the Georgetown University School of Medicine. JNB provided mentorship and edited the final paper. Both authors contributed toward data analysis, drafting and critically revising the paper, gave final approval of the version to be published, and agree to be accountable for all aspects of the work.

\section{Disclosure}

The authors report no conflicts of interest in this work.

\section{References}

1. Bansal AS. Investigating unexplained fatigue in general practice with a particular focus on CFS/ME. BMC Fam Pract. 2016;17:81.

2. Pitrou I, Lecourt AC, Bailly L, et al. Waiting time and assessment of patient satisfaction in a large reference Emergency Department: a prospective cohort study, France. Eur J Emerg Med. 2009;16(4):177-182.

3. Rhodes KV, Kushner HM, Bisgaier J, Prenoveau E. Characterizing Emergency Department discussions about depression. Acad Emerg Med. 2007;14(10):908-911.

4. Thompson DA, Yarnold PR, Williams DR, Adams SL. Effects of actual waiting time, perceived waiting time, information delivery, and expressive quality on patient satisfaction in the Emergency Department. Ann Emerg Med. 1996;28(6):657-665.

5. Krishel S, Baraff LJ. Effect of Emergency Department information on patient satisfaction. Ann Emerg Med. 1993;22(3):568-572.

6. Dinh MM, Enright N, Walker A, Parameswaran A, Chu M. Determinants of patient satisfaction in an Australian Emergency Department fast-track setting. Emerg Med J. 2013;30(10):824-827.
7. Abar B, Hong S, Aaserude E, Holub A, Derienzo V. Access to care and depression among Emergency Department patients. J Emerg Med. 2017;53(1):30-37.

8. Abar B, Holub A, Lee J, Derienzo V, Nobay F. Depression and anxiety among Emergency Department patients: utilization and barriers to care. Acad Emerg Med. 2017;24(10):1286-1289.

9. Clarke DE, Gonzalez M, Pereira A, et al. The impact of knowledge on attitudes of Emergency Department staff towards patients with substance related presentations: a quantitative systematic review protocol. JBI Database System Rev Implement Rep. 2015;13(10):133-145.

10. Asbring $P$, Närvänen AL. Women's experiences of stigma in relation to chronic fatigue syndrome and fibromyalgia. Qual Health Res. 2002;12(2):148-160.

11. Dickson A, Knussen C, Flowers P. Stigma and the delegitimation experience: an interpretative phenomenological analysis of people living with chronic fatigue syndrome. Psychol Health. 2007;22(7):851-867.

12. Fukuda K, Straus SE, Hickie I, et al. The chronic fatigue syndrome: a comprehensive approach to its definition and study. International Chronic Fatigue Syndrome Study Group. Ann Intern Med. 1994;121(12):953-959.

13. Reeves WC, Lloyd A, Vernon SD, et al. Identification of ambiguities in the 1994 chronic fatigue syndrome research case definition and recommendations for resolution. BMC Health Serv Res. 2003;3(1):25.

14. Jones JF, Lin JM, Maloney EM, et al. An evaluation of exclusionary medical/psychiatric conditions in the definition of chronic fatigue syndrome. BMC Med. 2009;7:57.

15. Greenberg DB. Neurasthenia in the 1980s: chronic mononucleosis, chronic fatigue syndrome, and anxiety and depressive disorders. Psychosomatics. 1990;31(2):129-137.

16. Holmes GP, Kaplan JE, Stewart JA, et al. A cluster of patients with a chronic mononucleosis-like syndrome. Is Epstein-Barr virus the cause? JAMA. 1987;257(17):2297-2302.

17. World Health Organization. International Classification of Diseases 11th edition. Available from: http://www.who.int/classifications/icd/ en/. Accessed July 17, 2017.

18. Reynolds GK, Lewis DP, Richardson AM, Lidbury BA. Comorbidity of postural orthostatic tachycardia syndrome and chronic fatigue syndrome in an Australian cohort. J Intern Med. 2014;275(4):409-417.

19. Carruthers BM. Myalgic encephalomyelitis/chronic fatigue syndrome: clinical working case definition, diagnostic and treatments protocols. $J$ Cfs. 2003;11:7-115.

20. Carruthers BM, van de Sande MI, de Meirleir KL, et al. Myalgic encephalomyelitis: International Consensus Criteria. J Intern Med. 2011;270(4):327-338.

21. Institute of Medicine. Beyond Myalgic Encephalomyelitis/Chronic Fatigue Syndrome: Redefining an Illness. Washington, DC: Institute of Medicine; 2015.

22. Ganiats TG. Redefining the chronic fatigue syndrome. Ann Intern Med. 2015;162(9):653-654.

23. Jason LA, Sunnquist M, Brown A, et al. Chronic fatigue syndrome versus systemic exertion intolerance disease. Fatigue. 2015;3(3):127-141.

24. Baraniuk JN, Adewuyi O, Merck SJ, et al. A Chronic Fatigue Syndrome (CFS) severity score based on case designation criteria. Am J Transl Res. 2013;5(1):53-68.

25. Brimmer DJ, Maloney E, Devlin R, et al. A pilot registry of unexplained fatiguing illnesses and chronic fatigue syndrome. BMC Res Notes. 2013;6:309.

26. International Association for Chronic Fatigue Syndrome/Myalgic Encephalomyelitis. Available from: http://iacfsme.org/ME-CFSPrimer-Education/News/News-Related-Docs/2014/ME-CFS-Primerfor-Clinical-Practitioners-(2014-rev.aspx. Accessed July 17, 2017.

27. Steele L. Prevalence and patterns of Gulf War illness in Kansas veterans: association of symptoms with characteristics of person, place, and time of military service. Am J Epidemiol. 2000;152(10):992-1002.

28. Rayhan RU, Zheng Y, Uddin E, Timbol C, Adewuyi O, Baraniuk JN. Administer and collect medical questionnaires with Google documents: a simple, safe, and free system. Appl Med Inform. 2013;33(3):12-21. 
29. Baraniuk JN. Chronic Fatigue Syndrome prevalence is grossly overestimated using the Oxford criteria compared to Center for Disease Control criteria in a U.S. population study. Fatigue: Biomedicine, Health \& Behavior. 2017;4:215-230.

30. American Psychiatric Association. Diagnostic and Statistical Manual of Mental Disorders (DSM-IV). 4th ed. Washington, DC: American Psychiatric Association; 1994.

31. Wegner M, Helmich I, Machado S, et al. Effects of exercise on anxiety and depression disorders: review of meta- analyses and neurobiological mechanisms. CNS Neurol Disord Drug Targets. 2014;13(6):1002-1014.

32. Fluge $\varnothing$, Mella O, Bruland $\mathrm{O}$, et al. Metabolic profiling indicates impaired pyruvate dehydrogenase function in myalgic encephalopathy/ chronic fatigue syndrome. JCI Insight. 2016;1(21):e89376.

33. Baraniuk JN, Murray RB, Mabbee WG, Ethanol MGW. Naloxone ethanol, and the chlorpropamide alcohol flush. Alcohol Clin Exp Res. 1987;11(6):518-520.

34. Newton JL, Mabillard H, Scott A, Hoad A, Spickett G. The Newcastle NHS chronic fatigue syndrome service: not all fatigue is the same. $J R$ Coll Physicians Edinb. 2010;40(4):304-307.

35. Evens A, Vendetta L, Krebs K, Herath P. Medically unexplained neurologic symptoms: a primer for physicians who make the initial encounter. Am J Med. 2015;128(10):1059-1064.

36. Lewis I, Pairman J, Spickett G, Newton JL. Clinical characteristics of a novel subgroup of chronic fatigue syndrome patients with postura orthostatic tachycardia syndrome. J Intern Med. 2013;273(5):501-510.

37. Lewis I, Pairman J, Spickett G, Newton JL. Is chronic fatigue syndrome in older patients a different disease? - a clinical cohort study. Eur J Clin Invest. 2013;43(3):302-308.

38. Newton JL, Okonkwo O, Sutcliffe K, et al. Symptoms of autonomic dysfunction in chronic fatigue syndrome. QJM. 2007;100(8):519-526.

39. Hollingsworth KG, Hodgson T, Macgowan GA, Blamire AM, Newton JL. Impaired cardiac function in chronic fatigue syndrome measured using magnetic resonance cardiac tagging. J Intern Med. 2012;271(3):264-270.

40. Miwa K, Fujita M. Small heart with low cardiac output for orthostatic intolerance in patients with chronic fatigue syndrome. Clin Cardiol. 2011;34(12):782-786.

41. Barnden LR, Kwiatek R, Crouch B, Burnet R, del Fante P. Autonomic correlations with MRI are abnormal in the brainstem vasomotor centre in Chronic Fatigue Syndrome. Neuroimage Clin. 2016;11:530-537.

42. Khan F, Kennedy G, Spence VA, Newton DJ, Belch JJ. Peripheral cholinergic function in humans with chronic fatigue syndrome, Gulf War syndrome and with illness following organophosphate exposure. Clin Sci. 2004;106(2):183-189.

43. Smith ME, Haney E, Mcdonagh M, et al. Treatment of myalgic encephalomyelitis/chronic fatigue syndrome: a systematic review for a national institutes of health pathways to prevention workshop. Ann Intern Med 2015;162(12):841-850.

44. Ravindran MK, Zheng Y, Timbol C, et al. Migraine headaches in Chronic Fatigue Syndrome (CFS). BMC Neurology 2011;11:30.

45. Rayhan RU, Ravindran MK, Baraniuk JN. Migraine in gulf war illness and chronic fatigue syndrome: prevalence, potential mechanisms, and evaluation. Front Physiol. 2013;4:181.

46. Arslanian-Engoren C, Patel A, Fang J, et al. Symptoms of men and women presenting with acute coronary syndromes. Am J Cardiol. 2006;98(9):1177-1181.

47. Mcmanimen SL, Devendorf AR, Brown AA, et al. Mortality in patients with myalgic encephalomyelitis and chronic fatigue syndrome. Fatigue. 2016;4(4):195-207.
48. Wolfe F, Clauw DJ, Fitzcharles MA, et al. Fibromyalgia criteria and severity scales for clinical and epidemiological studies: a modification of the ACR Preliminary Diagnostic Criteria for Fibromyalgia. J Rheumatol. 2011;38(6):1113-1122.

49. Wolfe F, Clauw DJ, Fitzcharles MA, et al. 2016 Revisions to the 2010/2011 fibromyalgia diagnostic criteria. Semin Arthritis Rheum. 2016;46(3):319-329.

50. Wolfe F, Smythe HA, Yunus MB, et al. The American College of Rheumatology 1990 Criteria for the Classification of Fibromyalgia. Report of the Multicenter Criteria Committee. Arthritis Rheum. 1990;33(2):160-172.

51. Wolfe F, Clauw DJ, Fitzcharles MA, et al. The American College of Rheumatology preliminary diagnostic criteria for fibromyalgia and measurement of symptom severity. Arthritis Care Res. 2010;62(5):600-610.

52. Wolfe F. Criteria for fibromyalgia? What is fibromyalgia? Limitations to current concepts of fibromyalgia and fibromyalgia criteria. Clin Exp Rheumatol. 2017;35(Suppl 105(3)):3-5.

53. Nater UM, Lin JM, Maloney EM, et al. Psychiatric comorbidity in persons with chronic fatigue syndrome identified from the Georgia population. Psychosom Med. 2009;71(5):557-565.

54. Skapinakis P, Lewis G, Mavreas V. Unexplained fatigue syndromes in a multinational primary care sample: specificity of definition and prevalence and distinctiveness from depression and generalized anxiety. Am J Psychiatry. 2003;160(4):785-787.

55. Iacob E, Light AR, Donaldson GW, et al. Gene expression factor analysis to differentiate pathways linked to fibromyalgia, chronic fatigue syndrome, and depression in a diverse patient sample. Arthritis Care Res. 2016;68(1):132-140.

56. Hardcastle SL, Brenu EW, Johnston S, et al. Longitudinal analysis of immune abnormalities in varying severities of Chronic Fatigue Syndrome/Myalgic Encephalomyelitis patients. JTransl Med. 2015;13:299.

57. Naviaux RK, Naviaux JC, Li K, et al. Metabolic features of chronic fatigue syndrome. Proc Natl Acad Sci U S A. 2016;113(37):E5472-E5480.

58. Kjaergaard M, Arfwedson Wang CE, Waterloo K, Jorde R. A study of the psychometric properties of the Beck Depression Inventory-II, the Montgomery and Åsberg Depression Rating Scale, and the Hospital Anxiety and Depression Scale in a sample from a healthy population. Scand J Psychol. 2014;55(1):83-89.

59. Screening for Depression in Adults: Recommendation Statement. Am Fam Physician. 2016;94(4). Available from: https:/www.aafp.org/ afp/2016/0815/od1.html. Accessed July 27, 2017.

60. Hoyer D, David E. Screening for depression in Emergency department patients. J Emerg Med. 2012;43(5):786-789.

61. Rund DA. Behavioral disorders: clinical features. In: Tintinalli JE, Kelen GD, Stapczynski JS, editors. Emergency Medicine: A Comprehensive Study Guide. 6th ed. Irving, TX: American College of Emergency Physicians; 2004;1810.

62. Takayanagi Y, Spira AP, Bienvenu OJ, et al. Antidepressant use and lifetime history of mental disorders in a community sample: results from the Baltimore Epidemiologic Catchment Area Study. J Clin Psychiatry. 2015;76(1):40-44.

63. Noakes TD. Fatigue is a brain-derived emotion that regulates the exercise behavior to ensure the protection of whole body homeostasis. Front Physiol. 2012;3:82.

64. Capelli E, Zola R, Lorusso L, et al. Chronic fatigue syndrome/myalgic encephalomyelitis: an update. Int J Immunopathol Pharmacol. 2010;23(4):981-989. 


\section{Publish your work in this journal}

The Open Access Emergency Medicine is an international, peerreviewed, open access journal publishing original research, reports, editorials, reviews and commentaries on all aspects of emergency medicine. The manuscript management system is completely online and includes a very quick and fair peer-review system, which is all

Submit your manuscript here: https://www.dovepress.com/open-access-emergency-medicine-journal

easy to use. Visit http://www.dovepress.com/testimonials.php to read real quotes from published authors. 